\title{
Winter temperature predicts prolonged diapause in pine processionary moth across its geographic range
}

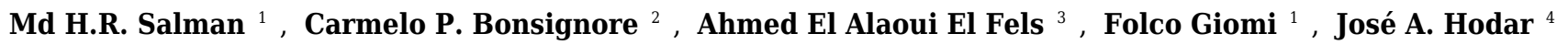

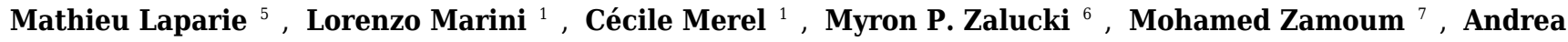
Battisti ${ }^{\text {Corresp. } 1}$

1 DAFNAE, University of Padova, Legnaro Padova, Italia

2 PAU, Università Mediterranea, Reggio Calabria, Italia

3 Faculté des Sciences, Université Cadi Ayyad, Marrakech, Morocco

4 Department of Ecology, Universidad de Granada, Granada, Spain

5 Department Zoologie forestiere, INRA, Orleans, France

${ }^{6}$ School of Biological Sciences, Queensland University, Brisbane, Australia

7 Arboretum Bajnem, Institut National Recherche Forestiere, Algiers, Algeria

Corresponding Author: Andrea Battisti

Email address: andrea.battisti@unipd.it

Prolonged diapause occurs in a number of insects and is interpreted as a way to evade adverse conditions. The winter pine processionary moths (Thaumetopoea pityocampa and Th. wilkinsoni) are important pest of pines and cedars in the Mediterranean region. They are typically univoltine, with larvae feeding across the winter, pupating in spring in the soil and emerging as adults in summer. Pupae may, however, enter a prolonged diapause with adults emerging one or more years later. We tested the effect of spatial variation in winter temperature on the incidence of prolonged diapause, using a total of 64 individual datasets related to insect cohorts over the period 1964-2015 for 36 sites in 7 countries, covering most of the geographic range of the species. We found high variation in prolonged diapause incidence over the species' range. Insect cohorts exposed to average winter temperatures lower than $0^{\circ} \mathrm{C}$ were associated with higher prolonged diapause incidence than cohorts exposed to intermediate temperatures. Prolonged diapause may represent a risk-spreading strategy although it is associated with high mortality because of a longer exposure to mortality factors, desiccation, and energy depletion. Climate change, and in particular the increase of winter temperature, may reduce the incidence of prolonged diapause at the colder sites whereas it may increase it at the warmer ones, with consequences on the population dynamics. 
1 Winter temperature predicts prolonged diapause in pine processionary moths species

2 across their geographic range

3

4 Md H.R. Salman ${ }^{1}$, Carmelo P. Bonsignore ${ }^{2}$, Ahmed El Alaoui El Fels ${ }^{3}$, Folco Giomi ${ }^{1}$, José A.

5 Hódar ${ }^{4}$, Mathieu Laparie ${ }^{5}$, Lorenzo Marini ${ }^{1}$, Cécile Merel $^{1}$, Myron P. Zalucki ${ }^{6}$, Mohamed

6 Zamoum $^{7}$ and Andrea Battisti ${ }^{1, *}$

7

8 1. DAFNAE, University of Padova, Legnaro Padova, Italia

9 2. PAU, Università Mediterranea, Reggio Calabria Italia

3. Faculté des Sciences, Université Cadi Ayyad, Marrakech, Morocco

4. Department of Ecology, Universidad de Granada, Granada, Spain

5. INRA, Unité de Recherche de Zoologie Forestière, INRA, Orléans, France

6. School of Biological Science, The University of Queensland, Brisbane, Australia

7. Arboretum Bajnem, Institut National Recherche Forestiere, Alger, Algeria

$16 *$ Author for correspondence:

Andrea Battisti

e-mail: andrea.battisti@unipd.it 


\section{Abstract}

23 Prolonged diapause occurs in a number of insects and is interpreted as a way to evade adverse conditions. The winter pine processionary moths (Thaumetopoea pityocampa and Th. wilkinsoni)

25 are important pest of pines and cedars in the Mediterranean region. They are typically univoltine, 26 with larvae feeding across the winter, pupating in spring in the soil and emerging as adults in

27 summer. Pupae may, however, enter a prolonged diapause with adults emerging one or more 28 years later. We tested the effect of variation in winter temperature on the incidence of prolonged diapause, using a total of 64 individual datasets related to insect cohorts over the period 19642015 for 36 sites in 7 countries, covering most of the geographic range of both species. We found high variation in prolonged diapause incidence over their ranges. At both lower and upper ends of the thermal range in winter, prolonged diapause tended to be higher than at intermediate temperatures. Prolonged diapause may represent a risk-spreading strategy to mitigate climate uncertainty, although it may increase individual mortality because of a longer exposure to mortality factors such as predation, parasitism, diseases or energy depletion. Climate change, and in particular the increase of winter temperature, may reduce the incidence of prolonged diapause

37 in colder regions whereas it may increase it in warmer ones, with consequences for population dynamics. 


\section{Introduction}

43 Although diapause is recognized as a common strategy among insects to overcome unfavourable

44 periods, few studies have focused on diapause spanning more than one year (Danks, 1987; Soula 45 and Menu, 2005). In general, diapause represents a break in development maximising the chance 46 to survive predictably adverse conditions (Tauber et al., 1986). By contrast, the expression of 47 prolonged diapause varies within a population and is generally considered a way to spread the risk due to variably unfavourable conditions amongst years (Menu et al., 2000). If organisms can use an external or internal signal to predict unfavourable conditions, which reduce fitness, phenotypic plasticity can intervene to minimize the costs (Pigliucci, 2001). In contrast, if unfavourable conditions cannot be predicted by any cues, their negative effect on fitness can be mitigated using a "risk-spreading" (den Boer, 1968), or "bet hedging" strategy (Slatkin, 1974). Prolonged diapause is a common example of risk-spreading in insects, as it creates heterogeneity within populations by extending the life cycle of a fraction of individuals which stay in a resistance form regardless of external conditions. In an environment with uncertain fluctuations, this strategy can be beneficial on the long term because it limits the worst-case scenarios of

57 massive mortality when all the offspring is exposed to an unpredicted stress. The added heterogeneity reduces between-individual variance in fitness in case of stress by increasing the geometric mean fitness in the long run (Seger and Brockmann, 1987; Starrfelt and Kokko, 2012). Individuals undergoing prolonged diapause may, however, suffer increased mortality (Sims, 1983) or reduced performance (Matsuo, 2006) compared to their counterparts, because they spend energy (Hahn and Denlinger, 2007) and are exposed to adverse factors and natural enemies for longer durations. 
If resource availability or some other essential environmental factors show a strong

65

66

67

68

multiannual cyclic component, a large part of the individuals in a population may enter prolonged diapause, such as in yucca moth depending on inflorescence availability in desert areas (Powell, 1974), or in cone insects depending on bumper crop years in boreal forests (Hanski, 1988). More irregular conditions may lead to more variation in the expression of prolonged diapause within the same population because the variance balances the fitness costs and benefits of the extended cycle when risks are uncertain. Whether the diapause attitude can be inherited has been discussed in the literature, but there is no clear data available (Tauber and Tauber, 1981; French et al. 2014). Maternal effects have been considered, especially in relation to abiotic (climate) and biotic (nutrition, diseases) conditions experienced by the parents (Mousseau and Dingle, 1991; Denlinger, 2002). Overall, climate plays a major role in all ectotherm life-histories and affects populations in a way that is generally independent of density, whereas biotic factors are strictly linked to population density and can thus be more predictable (Hanski, 1988).

In Europe, Middle East, and Northern Africa, the winter pine processionary moths are represented by two sister species, Thaumetopoea pityocampa and Th. wilkinsoni (Lepidoptera, Notodontidae), which are pests of conifers and a threat to human and animal health because of urticating setae (Roques, 2015). Larvae feed during winter and generally adopt a univoltine life cycle, with the exception of Corsica where Th. pityocampa is strictly semivoltine (Geri, 1983). Temperature influences the duration of both larval and pupal stages (Démolin, 1969; Berardi et al., 2015; Robinet et al., 2015). After completing their development in silk tents, larvae leave the host tree in a typical head-to-tail procession in search of a suitable pupation site in the soil. Burying 5-20 cm into the soil, they spin a cocoon and enter a phase of prepupal diapause, 
87 spanning 20 to 50 days (Salman et al., 2018). Breaking their prepupal diapause, univoltine

88

89

90

91

92

93

94

95

96

97

98

individuals turn into pupae and enter a pupal diapause ranging from 1 month at high

elevations/latitudes to 5 months at low elevations or latitudes. Such a difference in duration has been interpreted as a way to optimize the larval development in the next generation (Démolin, 1969; Robinet et al., 2015). The duration of this pupal diapause appears genetically determined, as populations from different elevations or latitudes reared under the same conditions over a few generations maintain their typical phenology (Petrucco-Toffolo et al., 2018). Moths generally emerge in summer, but a variable fraction of the individuals may postpone their emergence and enter a prolonged pupal diapause that may last, as far as we know, up to 9 years in Th. wilkinsoni (Halperin, 1990) and 8 years in Th. pityocampa (Salman et al., 2016).

The mechanisms inducing and maintaining prolonged diapause in the winter pine processionary moths are unknown and do not appear to be genetically determined like normal pupal diapause. However, a temperature-based hypothesis suggests that prolonged diapause in the pine processionary moths is a developmental strategy to cope with adverse temperature conditions, at both ends of the scale (Démolin, 1969). It suggests that the onset of summer is too hot for the normal development of eggs and young larvae at the lower/southern edge of the range, whereas the winter is too cold for further larval development at the upper/northern edge (Démolin, 1969; Robinet et al., 2015). Soil moisture (Torres-Muros et al., 2017), food quality or availability (Battisti, 1988), population density, and natural enemies have been proposed as additional factors influencing the expression of prolonged diapause (Geri, 1983), but remain to be experimentally demonstrated. Battisti et al. (2005) identified the temperature of the so-called 'cold period' (December-January-February) as a key predictor for larval survival, showing that 
109 climate change at both high elevation and latitude close to the range edges can trigger the

110 successful establishment beyond the past range and cause the current expansion of this pest.

111 Here, to test the temperature hypothesis proposed by Démolin (1969), we collected and

112 analysed all the available evidence of prolonged diapause across the range of Th. pityocampa and

113 Th. wilkinsoni, taking into account the genetic structure of the group (Kerdelhué et al., 2009; El

114 Mokhefi et al., 2016). Populations of Th. pityocampa from Corsica were excluded because of

115 their strict semivoltinism (Geri, 1983). We specifically tested the effect of winter temperature as

116 a driver of prolonged diapause in these species, and the costs of prolonged diapause in terms of

117 mortality. We finally discuss the role of climate change on prolonged diapause and the potential

118 effects on the population dynamics of these important pests.

121 Materials and methods

(a) Data collection

123 Published and unpublished data (initial available documents, $n=42$ ) were retrieved from

124 scientific databases and from institutional reports. Because we hypothesized winter temperature

125 to be a mechanism causing prolonged diapause, we only selected studies that met the following

126 criteria: (i) the total number of individuals is given, (ii) insects are collected using one or more of

127 the five methods described below, (iii) the number of moths emerged in the year of collection

128 and in the subsequent year(s) is given, (iv) the number of dead larvae/pupae is given for a

129 specific year of sampling (hereafter referred to as a cohort), and (v) the average air temperature

130 of the cold period (December-January-February) of the studied years is given. Information was

131 obtained for seven countries from a total of 13 documents and 36 sites in the period 1964-2015 
132 (Figure 1, Table 1, Supplemental file Dataset_S1). These sites belong to 6 out of 11 genetic

133 subclades of the pine processionary moths described by Kerdelhué et al. (2009) and El Mokhefi

134 et al. (2016) (Figure 1) and cover most of the climatic range of the species (Roques, 2015). The

135 data span latitudes from $31.3^{\circ} \mathrm{N}$ to $47.8^{\circ} \mathrm{N}$, longitudes from $-7.9^{\circ}$ to $35.2^{\circ}$ (Figure 1 ), and

136 elevations from 10 to $1910 \mathrm{~m}$. For 11 sites, more than one year (up to six) of observations was

137 available, giving a total of 64 individual datasets on the occurrence of prolonged diapause.

138 For the year(s) of sampling, the temperature of each site was collected from the source

139 document $(n=41)$ or from records of the nearest weather station $(n=23)$ (Supplemental file

140 Dataset_S3). Average monthly temperature of the cold period (December-January-February)

141 (Battisti et al., 2005; Roques, 2015) was available for all datasets and was included in the

142 analyses. For those sites with both average and minimum temperature, the correlation between

143 the two predictors was very strong $\left(\mathrm{R}^{2}=0.94\right)$, indicating that the choice of either metric would

144 only marginally affect the results.

The mortality percentage was calculated as the number of individuals that did not

146 produce moths with respect to the initial number of individuals in the cohort. The prolonged

147 diapause percentage was calculated as the number of individuals that emerged over the year(s)

148 following the year of pupation, or that were still alive when the experiment was over one or more

149 years after pupation (emerged after prolonged diapause + living pupae at the last check), with

150 respect to the total number of emerged or living individuals (emerged univoltine + emerged after

151 prolonged diapause + living pupae at the last check).

152

Five collection methods were used: (i) digging out pupae from natural pupation sites

153 previously marked by following mature larvae during their processions until they started to bury

154 themselves; (ii) collecting mature larvae during their pupation processions on the ground before 
155 they bury and placing them in pots with substrate to stimulate pupation; (iii) intercepting mature

156 larvae at the beginning of their procession on tree trunks with collar traps during their way down

157 to the ground, and placing them in mesh-capped pots or geotextile bags with substrate to

158 stimulate pupation, on site or at the laboratory; (iv) collecting tents full of mature larvae ready

159 for processions, placing them in outdoor cages or mesh-capped pots with substrate, separately or 160 clustered, until pupation; (v) collecting tents with $4^{\text {th }}$ or $5^{\text {th }}$ instar larvae, placing them in outdoor 161 cages or mesh-capped pots with substrate, separately or clustered, and supplying fresh pine

162 foliage ad libitum until pupation. The year of pupation was known for each colony and it was

163 then possible to discriminate univoltine adults emerging in the same year from those emerging in

164 the following year(s) after prolonged diapause. Insects collected using methods (i) and (iii) were

165 individually placed in glass vials in the laboratory for future monitoring as soon as they pupated

166 in the field, while those collected using method (ii) were placed in vials only after the univoltine

167 adults emerged. Individuals collected using methods (iv) and (v) and placed in field cages were

168 left and monitored there, while those placed in pots were either left in the substrate or transferred

169 to glass vials after univoltine adults emerged. The monitoring was carried out until no emergence 170 was observed for three consecutive years.

172 (b) Data analysis

173 To test the effect of temperature on prolonged diapause incidence, we used a linear mixed-effect

174 model (Supplemental file Dataset_S2). The model included the linear, quadratic and cubic terms 175 of temperature as fixed effects and site nested within genetic subclade as random effect. We 176 omitted one data point using Cook's distance (value $>5$ ). This very influential point was related 177 to the maximum observed mean temperature. The consideration of subclade and site as random 
178 effects accounted for the biological and spatial dependence in the data. It is important to stress

179 that our model tested primarily the effect of spatial variation in winter temperature across the

180 species' ranges, and only secondarily the inter-annual variation in temperature within the sites.

181 The analyses were run using the nlme package in $R$ (Supplemental file Dataset_S3) (R Core

182 Team 2016). A model with the same random structure was used to test the association between

183 the incidence of prolonged diapause and pupal mortality.

184

185

186

187

188

189

190

191

192

193

194

195

196

197

198

199

\section{Results}

Prolonged diapause occurred in all genetic subclades of Th. pityocampa and Th. wilkinsoni for which data were available (Figure 2a). All 37 sites showed at least one year with occurrence of prolonged diapause, and only 5 out of 65 individual datasets or cohorts did not show prolonged diapause. The incidence of prolonged diapause in the first year after pupation varied greatly in time and space. The mixed model indicated that temperature affected the incidence of prolonged diapause in a non-linear fashion, i.e. linear $\left(\mathrm{t}_{1,25}=-5.481, \mathrm{P}<0.001\right)$, quadratic $\left(\mathrm{t}_{1,25}=-3.687, p=\right.$ $0.001)$ and cubic terms $\left(\mathrm{t}_{1,25}=-2.395, p=0.025\right)$ were significant. Both cold winters (temperature of December-January-February around $0^{\circ} \mathrm{C}$ ) and warm winters (above $10^{\circ} \mathrm{C}$ ) resulted in a high incidence of prolonged diapause, whereas intermediate winters (between 2 and $10^{\circ} \mathrm{C}$ ) resulted in less frequent prolonged diapause, irrespective of subclades (Figure 2a). However, the effect of warm winters was less pronounced than that of cold winters. The 5 datasets with no occurrence of prolonged diapause and almost all those with less than $25 \%$ of prolonged diapause were observed at temperatures between 2 and $10^{\circ} \mathrm{C}$ (Figure $2 \mathrm{a}$ ). 
incidence (Figure 2b). Mortality varied greatly in time and space. It reached the highest values at both cold (around $0^{\circ} \mathrm{C}$ ) and warm (above $10^{\circ} \mathrm{C}$ ) winter sites, indicating that individuals in cohorts showing a high incidence of prolonged diapause are more likely to die than those showing a low incidence. Mortality rates lower than $25 \%$ were associated with low incidence of prolonged diapause, especially in the subclade Rest of Europe. The mortality factors were not systematically addressed in each study, so it was not possible to compare their relative effects.

\section{Discussion}

Winter temperature experienced by larvae was found to be a reliable predictor of the prolonged diapause incidence in the winter pine processionary moths pupae: prolonged diapause tends to increase at both lower and upper ends of the thermal range in winter, although the incidence remained highly variable among samples. The adaptive value of prolonged diapause in this species can be seen at both ends of the temperature range, presumably for different reasons. In colder sites and years, the harsh winter challenges larval survival that depends essentially on reaching thermal feeding thresholds (Battisti et al., 2005). Prolonged diapause in this case dilutes the risk of being exposed again to long starvation associated with unusually cold weather among years (Danks, 1987; Battisti et al., 2005). In warmer sites and years, peaking summer temperatures are assumed to overreach upper thermal limits of eggs and young larvae and impair their survival (Halperin, 1990; Santos et al., 2011). In this case winter temperature works as a

221 proxy of another thermal stressor that could become limiting later in the year when moths would

222 emerge and lay eggs. Thus, entering prolonged diapause at the southern edge of the range where 
223 both winter and summer tend to be warmer would allow spreading the risk through time and

224 facilitate the persistence of populations (Hanski, 1988). Slight thermal changes may drastically

225 influence the survival rate in populations close to their biological limits. This is particularly

226 problematic at the edge of the distribution range (Renault et al. 2018). In such conditions where

227 the thermal margin is low, weather conditions may exceed biological limits any year. Therefore,

228 prolonged diapause in a fraction of individuals, even at a moderate temperature generally

229 deemed harmless for growth and survival, may often be the safest bet. This strategy differs from

230 that of other Lepidoptera that use a fixed prolonged diapause to synchronize with the availability

231 of resources, such as the yucca inflorescences for yucca moth (Powell, 1974) and the spruce seed

232 cones for the seed cone moth (Hanski, 1988).

233 Variance in prolonged diapause duration could not be tested in this study because most

234 reports did not survey the emergence of the moths for more than three years. As durations up to

235 8-9 years have been found at a few sites (Halperin, 1990; Salman et al., 2016), an hypothesis is

236 that the intensity of the winter stress could be proportional to the duration of prolonged diapause,

237 causing a higher variance and a longer dilution of the risk in the most severe conditions. In

238 addition, high density of larvae would result in higher incidence of prolonged diapause, as

239 damaged trees may be unpalatable for the larvae of the following generations (Battisti, 1988).

240 The higher the density of larvae, the higher the unpalatability of needles, the longer would be the

241 diapause (Salman et al., 2016). This sort of density-dependent prolonged diapause could

242 combine with mechanisms induced by abiotic stresses, e.g., temperature. Unfortunately, many

243 studies on prolonged diapause examined in the present work did not report population density at

244 the time of sampling. Other putative factors (such as epidemics, predation and parasitism) may

245 respond to density variation, with or without lag effects, and thus prolonged diapause can be 
246 hypothesized as an escape in time from such biotic lethal factors (Hanski, 1988). Numerous

247 parasitoids and predators of the pine processionary moth are univoltine and cannot track and

248 keep synchronization with individuals entering prolonged diapause (Battisti et al., 2000).

249 Irrespective of the thermal conditions, pupal mortality increased with prolonged diapause

250 incidence likely because of a longer exposure to chronic mortality factors (Sims, 1983),

251 including natural enemies or depletion of energy reserves (Hahn and Denlinger, 2011). These

252 higher mortality risks associated with prolonged diapause are expected and important but they do

253 not contradict the benefits of prolonged diapause as a diversifying risk-spreading strategy. In

254 fact, more attention should be given to climatically non-typical years when benefits of such a

255 strategy would be expected, ultimately securing the survival of part of the offspring and long

256 term persistence of populations (Menu et al., 2000). Prolonged diapause could also limit the risks

257 of local extinction after the generally high mortality observed at outbreak density (Tamburini et

258 al., 2013; Li et al., 2015; Salman et al., 2016). Survival, rather than reproduction, is more

259 important in a declining population or a population close to its ecological limits, and is secured

260 by entering prolonged diapause. However, whether increased frequency of prolonged diapause

261 contributes to declining population growth rates or the other way around, is still not clear

262 (Hanski, 1988). In addition, the phenology of the winter pine processionary moths is severely

263 constrained by climatic factors (Robinet et al., 2015), and it could be that in certain years the

264 required physiological conditions to complete univoltine development are not met, thus leaving

265 no alternative to prolonged diapause that eventually may become fixed as in Corsica mountains

266 (Geri, 1983).

Climate change may affect prolonged diapause in different ways. As winter is

experienced in two different life stages, the growing larva and the pupa undergoing prolonged 
269 diapause, it is likely that their respective vulnerability to stressful conditions differ. Larvae

270 feeding on trees are exposed to low, fluctuating temperatures, but are capable of selecting

271 suitable microclimates and have a silk tent helping to regulate temperature (Battisti et al., 2005),

272 while pupae in the soil are passively buffered against temperature extremes. In addition, both

273 stages have complex interactions with precipitation and moisture, and related pathogenic agents

274 (Torres-Muros et al., 2017). Observations carried out between 1999 and 2016 in the coldest edge

275 of the species' geographical range in the Alps indicated that prolonged diapause incidence

276 markedly decreased as a consequence of climate warming (Salman et al., 2016). This observation

277 is congruent with our finding that prolonged diapause likely mitigates the risk associated with

278 low winter temperatures in cold areas of the distribution, since winter warming lowers the

279 climatic barrier. Likewise, future studies should test whether climate warming in warm areas of

280 the range intensifies the risks associated with summer heats and increase the incidence to

281 prolonged diapause, as predicted by our results. Such changes in the incidence of prolonged

282 diapause, and related mortality, have to be taken into consideration when modelling population

283 dynamics and range expansion, since prolonged diapause can alter the long term success of a

284 population in a given area ( $\mathrm{Li}$ et al., 2015). For example, a reduction of prolonged diapause

285 incidence would make predictions easier because it will emphasize the role of density-dependent

286 factors, which are important in this species (Tamburini et al., 2013; Toïgo et al., 2017).

287

288

289

290

291

\section{Conclusion}

Winter temperature variation across both species range is an important extrinsic factor for geographic variation in prolonged diapause incidence. While prolonged diapause was minimal in 
292 areas where winters are intermediate, both low and high winter temperatures are conducive to

293 high frequency of prolonged diapause in pupae, likely because of different avoidance

294 mechanisms of lower and upper biological limits in different insect life stages. A number of

295 other factors (such as genetic determination, parasitism, predation, diseases, intraspecific

296 competition) have to be considered, however, for a better understanding of the physiological

297 mechanism regulating prolonged diapause in winter pine processionary moths. In particular,

298 population density and nutritional status of larvae before pupation may reveal the role of

299 prolonged diapause in the population dynamics of this important defoliating pest.

300

301

302

\section{Acknowledgements}

303

The authors warmly acknowledge Philipp Lehmann for comments on an earlier version of the ms

304 and Paolo Paolucci for drawing the figures. Anonymous reviewers are also warmly

305 acknowledged.

306

307

308

\section{References}

309

310

311

312

313

314

Battisti A. 1988. Host-plant relationships and population dynamics of the Pine Processionary Caterpillar Thaumetopoea pityocampa (Denis \& Schiffermüller). Journal of Applied Entomology 105:393-402.

Battisti A, Bernardi M, Ghiraldo C. 2000. Predation by the hoopoe (Upupa epops) on pupae of Thaumetopoea pityocampa and the likely influence on other natural enemies. BioControl 45:311-323. 
315 Battisti A, Stastny M, Netherer S, Robinet C, Schopf A, Roques A, Larsson S. 2005. Expansion 316 of geographic range in the pine processionary moth caused by increased winter temperatures. Ecological Applications 15:2084-2096.

318

319

320

321

322

323

324

325

326

327

328

329

330

331

332

333

334

335

336

Berardi L, Branco M, Paiva MR, Santos H, Battisti A. 2015. Development time plasticity of the pine processionary moth (Thaumetopoea pityocampa) populations under laboratory conditions. Entomologia 3:273.

Boer den PJ. 1968. Spreading of risk and stabilization of animal numbers. Acta Biotheoretica 18:165-194.

Danks HV. 1987. Insect dormancy: an ecological perspective. Ottawa: Biological Survey of Canada.

Démolin G. 1969. Bioecologia de la procesionaria del pino Thaumetopoea pityocampa Schiff. Incidencia de los factores climaticos. Boletin del Servicio de Plagas Forestales 12:9-24.

Denlinger DL. 2002. Regulation of diapause. Annual Review of Entomology 47:93-122.

El Mokhefi M, Kerdelhué C, Burban C, Battisti A, Chakali G, Simonato M. 2016. Genetic differentiation of the pine processionary moth at the southern edge of its range: contrasting patterns between mitochondrial and nuclear markers. Ecology and Evoution 6:4274-4288.

French BW, Coates BS, Sappington TW. 2014. Inheritance of an extended diapause trait in the Northern corn rootworm, Diabrotica barberi (Coleoptera: Chrysomelidae). Journalof Applied Entomology 138:213-221.

Geri C. 1983. Distribution and evolution of populations of the pine processionary, Thaumetopoea pityocampa Schiff, (Lep., Thaumetopoeidae) in the Corsican mountains. I. 
337 338

339 340

Emergence rhythms of the insect and population dynamics. Acta Oecologica Oecologia Applicata 4:247-268.

Hahn DA, Denlinger DL. 2007. Meeting the energetic demands of insect diapause: nutrient storage and utilization. Journal of Insect Physiology 53:760-773.

Hahn DA, Denlinger DL. 2011. Energetics of insect diapause. Annual Review of Entomology $56: 103-121$

Halperin J. 1990. Life history of Thaumetopoea wilkinsoni in Israel. Journal of Applied Entomology 110:1-6.

Hanski I. 1988. Four kinds of extra long diapause in insects: a review of theory and observations. Annales Zoologici Fennici 25:37-53.

Kerdelhué C, Zane L, Simonato M, Salvato P, Rousselet J, Roques A, Battisti A. 2009. Quaternary history and contemporary patterns in a currently expanding species. $B M C$ Evolutionary Biology 9:1-14.

Li S, Daudin JJ, Piou D, Robinet C, Jactel H. 2015. Periodicity and synchrony of pine processionary moth outbreaks in France. Forest Ecology and Management 354:309-317.

Matsuo Y. 2006. Cost of prolonged diapause and its relationship to body size in a seed predator. Functional Ecology 20:300-306.

Menu F, Roebuck J, Viala M. 2000. Bet-hedging diapause strategies in stochastic environments. American Naturalist 155:724-734.

Mousseau TA, Dingle H. 1991. Maternal effects in insect life histories. Annual Review of Entomology 36:511-534. 
358 Petrucco-Toffolo E, Basso A, Kerdelhué C, Ipekdal K, Mendel Z, Simonato M, Battisti A. 2018.

$359 \quad$ Evidence of potential hybridization in the Thaumetopoea pityocampa-wilkinsoni 360 complex. Agricultural and Forest Entomology 20:9-17.

361 Pigliucci M. 2001. Phenotypic plasticity: beyond nature and nurture. Baltimore: John Hopkins $362 \quad$ University Press.

363 Powell JA. 1974. Occurrence of prolonged diapause in ethmiid moths. Pan-Pacific Entomology 364 50:220-225.

365

366

367

368

369

370

371

372

373

374

375

376

377

378

379

R Core Team 2016. R: A language and environment for statistical computing. R Foundation for Statistical Computing, Austria. URL https://www.R-project.org/

Renault D, Laparie M, McCauley SJ, Bonte D. 2018. Environmental adaptations, ecological filtering, and dispersal central to insect invasions. Annual Review of Entomology 63 :345368.

Robinet C, Laparie M, Rousselet J. 2015. Looking beyond the large scale effects of global change: local phenologies can result in critical heterogeneity in the pine processionary moth. Frontiers in Physiology 6:334.

Roques A. 2015. Processionary Moths and Climate Change: An Update. Dordrecht: Springer.

Salman MHR, Hellrigl K, Minerbi S, Battisti A. 2016. Prolonged pupal diapause drives population dynamics of the pine processionary moth (Thaumetopoea pityocampa) in an outbreak expansion area. Forest Ecology and Management 361:375-381.

Salman MHR, Giomi F, Laparie M, Lehmann P, Battisti A. 2018. Prepupal diapause synchronizes adult emergence in the pine processionary moth Thaumetopoea pityocampa (Lepidoptera: Notodontidae). Agricultural and Forest Entomology 20:582-588. 
380 Santos H, Paiva MR, Tavares C, Kerdelhué C, Branco M. 2011. Temperature niche shift

381 observed in a Lepidoptera population under allochronic divergence. Journal of Evolutionary Biology 24:1897-1905.

383

384

385

386

387 388

389

390

391

392

393

394

395

396

397

398

399

400

401

Seger J, Brockmann HJ. 1987. What is bet-hedging? Oxford Surveys in Evolutionary Biology 4:182-211.

Sims SR. 1983. Prolonged diapause and pupal survival of Papilio zelicaon Lucas (Lepidoptera: Papilionidae). Journal of the Lepidopterists' Society 37:29-37.

Slatkin M. 1974. Hedging one's evolutionary bets. Nature 250:704-705.

Soula B, Menu F. 2005. Extended life cycle in the chestnut weevil: prolonged or repeated diapause? Entomologia Experimentalis et Applicata 115:333-340.

Starrfelt J, Kokko H. 2012. Bet-hedging - a triple trade-off between means, variances and correlations. Biological Review 87:742-755.

Tamburini G, Marini L, Hellrigl K, Salvadori C, Battisti A. 2013. Effects of climate and densitydependent factors on population dynamics of the pine processionary moth in the Southern Alps. Climatic Change 121:701-712.

Tauber CA, Tauber MJ. 1981. Insect seasonal cycles: genetics and evolution. Annual Review of Ecology and Systematics 12:281-308.

Tauber M J, Tauber CA, Masaki S. 1986. Seasonal adaptations of insects. New York: Oxford University Press.

Toïgo M, Barraquand F, Barnagaud J-Y, Piou D, Jactel H. 2017. Geographical variation in climatic drivers of the pine processionary moth population dynamics. Forest Ecology and Management 404:141-155. 
402 Torres-Muros L, Hódar JA, Zamora R. 2017. Effect of habitat type and soil moisture on pupal 403 stage of a Mediterranean forest pest (Thaumetopoea pityocampa). Agricultural and 404 Forest Entomology 19:130-138. 


\section{Captions}

406

407 Table 1:

408 Distribution of the 37 study sites among genetic clades and subclades of pine processionary 409 moths according to Kerdelhué et al. (2009) and El Mokhefi et al. (2016). The time period of 410 sampling and the pine host species are also given.

411

412 Figure 1:

413 Sites used for the analysis of prolonged diapause at the pupal stage, indicated with coloured dots

414 within each species and subclade of the pine processionary moth (a), and tree of genetic structure 415 based on Kerdelhué et al. (2009) and El Mokhefi et al. (2016) (b). Data were not available for the 416 subclades indicated in black.

418 Figure 2:

419 (a) Relationship between the daily mean temperature during the cold period of the larval 420 development (December, January, and February) and the percentage of prolonged diapause in the 421 cohorts of pupae originating from larvae experiencing those temperatures. The fitted line 422 represents predictions of a mixed model including subclade and site as random effects (Diapause $423=80.39-28.69 \mathrm{Temp}+3.96 \mathrm{Temp}^{2}-0.15 \mathrm{Temp}^{3}$, all terms $\left.\mathrm{p}<0.05, \mathrm{n}=64\right)$.

424 (b) Relationship between the percentage of individuals entering prolonged diapause and the 425 pupal mortality observed in the first year of prolonged diapause. The fitted line represents a 426 prediction of a mixed model including subclade and site as random effects (Mortality $=37.88+$ 4270.364 Diapause, $\mathrm{p}<0.001, \mathrm{n}=62)$. 


\section{Table $\mathbf{1}$ (on next page)}

Summary list of the study sites

Distribution of the 37 study sites among genetic clades and subclades of pine processionary moths according to Kerdelhué et al. (2009) and El Mokhefi et al. (2016). The time period of sampling and the pine host species are also given. 
1

2

\begin{tabular}{llccl}
\hline Clade & Subclade & No. of sites & Years & Host plant \\
\hline Th. pityocampa & Rest of Europe & 14 & $1971-2015$ & $\begin{array}{l}\text { P. halepensis } \\
\text { P. nigra } \\
\text { P. pinaster }\end{array}$ \\
\hline Th. pityocampa & $\begin{array}{l}\text { N/W Algeria, } \\
\text { N Morocco }\end{array}$ & 13 & 1988 & P. halepensis \\
\hline Th. pityocampa & $\begin{array}{l}\text { S Algeria, } \\
\text { S Morocco }\end{array}$ & 3 & $1988-1995$ & $\begin{array}{l}\text { Cedrus atlantica } \\
\text { P. halepensis }\end{array}$ \\
\hline Eastern North Africa & $\begin{array}{l}\text { N/E Algeria, } \\
\text { Tunisia }\end{array}$ & 4 & 1983 & P. halepensis \\
\hline Th. wilkinsoni & $\begin{array}{l}\text { Israel, Lebanon, } \\
\text { E Turkey }\end{array}$ & 3 & $1964-1970$ & P. halepensis \\
\hline
\end{tabular}

3

4 


\section{Figure 1 (on next page)}

Location of the study sites in relation to the distribution of the pine processionary moth

Sites used for the analysis of prolonged diapause at the pupal stage, indicated with coloured dots within each species and subclade of the pine processionary moth (a), and tree of genetic structure based on Kerdelhué et al. (2009) and El Mokhefi et al. (2016) (b). Data were not available for the subclades indicated in black. 


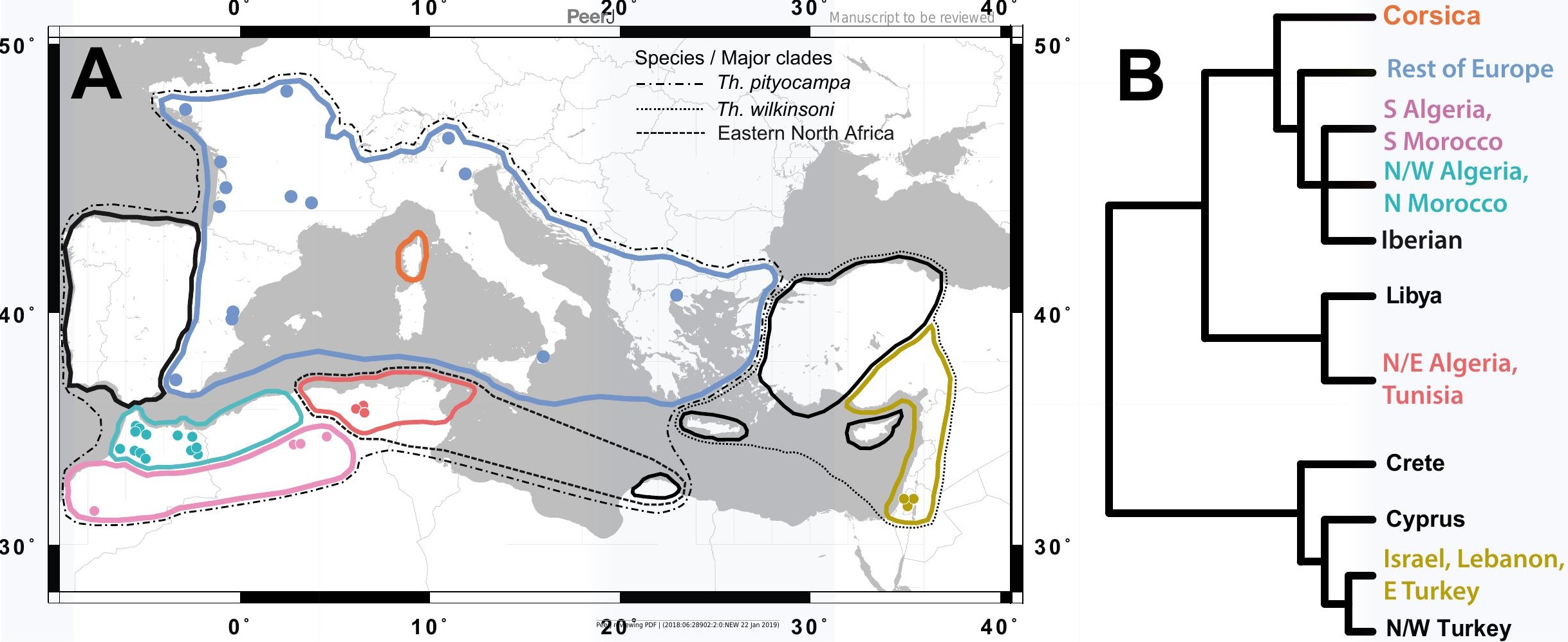




\section{Figure 2}

Variation of prolonged diapause rate in relation to winter temperature and relationships between prolonged diapause and pupal mortality

(a) Relationship between the daily mean temperature during the cold period of the larval development (December, January, and February) and the percentage of prolonged diapause in the cohorts of pupae originating from larvae experiencing those temperatures. The fitted line represents predictions of a mixed model including subclade and site as random effects (Diapause $=67.02-12.50 \mathrm{Temp}+0.85 \mathrm{Temp}^{2}$, both terms $\mathrm{P}<0.001, \mathrm{R}^{2}=0.32, \mathrm{n}=65$ ).

(b) Relationship between the percentage of individuals entering prolonged diapause and the pupal mortality observed in the first year of prolonged diapause. The fitted line represents a prediction of a mixed model including subclade and site as random effects (Mortality $=37.88+0.364$ Diapause, $P<0.001, R^{2}=0.18$, $n=65$ ).
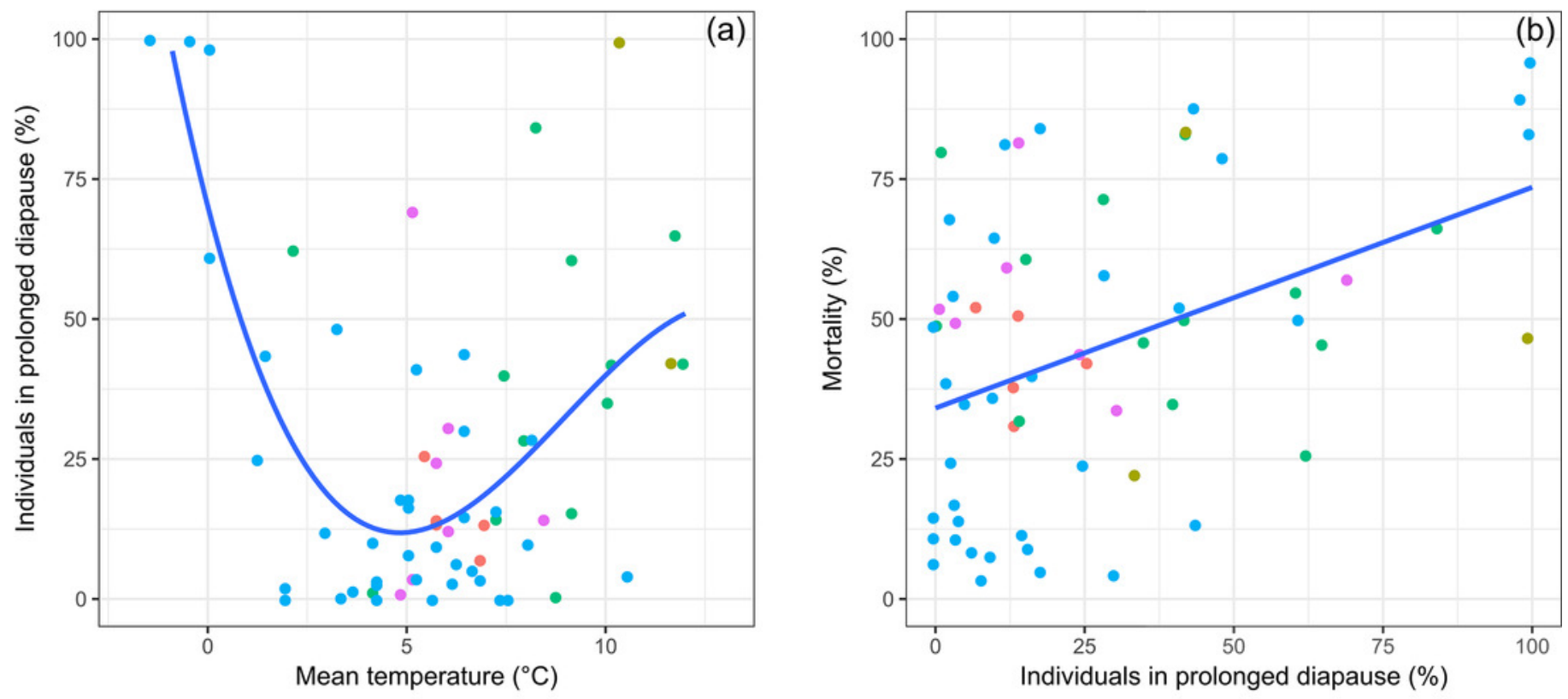

Subclade

- N/E Algeria and Tunisia

- Israel, Lebanon and E Turkey
- N/E Algeria and Morocco

- Rest of Europe

- South Algeria, South Morocco 